\title{
Koşullu Öz-Değer, Riskli İnternet Davranışları ve Siber Zorbalık/Mağduriyet Arasındaki İlişskinin İncelenmesi ${ }^{*}$
}

\author{
Yüksel EROĞLU**
}

Neşe GÜLER ${ }^{* * *}$

Öz

$\mathrm{Bu}$ araştırmanın amacı riskli internet davranışları, içsel ve dışsal koşullu öz-değer alanlarının siber zorbalık ve mağduriyet üzerindeki etkisini incelemektir. Bu araştırmaya Sakarya Üniversitesi'nin çeşitli bölümlerinde okuyan 505 öğrenci katılmıştır. Katılımcılara Kişisel Bilgi Formu, Koşullu ÖzDeğer Ölçeği, Riskli İnternet Davranışları Anketi ve Revize Edilmiş Siber Zorbalık Envanteri uygulanmıştır. Riskli internet davranışlarının ve içsel ve dışsal öz-değer alanlarının siber zorbalıkla ilişkili davranışlar üzerindeki etkisi yapısal eşitlik modellemesi yoluyla incelenmiştir. Yapısal eşitlik modelinde içsel öz-değer alanları erdem ve aile desteği, dışsal öz-değer alanları ise akademik yeterlik, onay alma ve rekabet değişkenlerinden oluşturulmuştur. Ayrıca koşullu öz-değer alanları, riskli internet davranışları, siber zorbalık ve siber mağduriyet arasındaki ilişkileri incelemek için Pearson korelasyon katsayısı kullanılmıştır. Modelin uyum iyiliği indeksleri $(\chi 2 / \mathrm{sd}=2.80, p=.000$ RMSEA=.06, \% 90 RMSEA CI $=.055-.064, \mathrm{CFI}=.92, \mathrm{TLI}=.91$, RMR=.06 ve SRMR=.06) modelin kabul edilebilir düzeyde olduğunu göstermektedir. Yol analizi sonuçlarına göre siber zorbalığı ve mağduriyeti; riskli internet davranışları ve dışsal öz-değer alanları pozitif, içsel öz-değer alanları ise negatif yönde yordamaktadır. Kurulan yapısal eşitlik modeli siber zorbalığın/mağduriyetin \%42'sini açılamaktadır. Bu bulgular alanyazın eşliğinde tartışılmıştır.

Anahtar Kelimeler: Siber zorbalık, riskli internet davranışları, koşullu öz-değer.

\section{The Investigation Relationships Among Contingencies of Self-Worth, Risky Internet Behaviors and Cyberbullying/Cybervictimization}

\begin{abstract}
The aim of this study was to examine relationships among risky internet behaviors, internal and external contingencies of self-worth, and cyberbullying and cybervictimization. 505 undergradute students from different departments of University of Sakarya participated in this study. The Sociodemographic Form, the Contingencies of Self-Worth Scale, the Risky Internet Behaviors Questionnaire, and the Revised Cyberbullying Inventory were applied to participants. The effect of risky in-
\end{abstract}

\footnotetext{
* Bu çalışma Yüksel Eroğlu'nun Yrd. Doç.Dr. Neşe Güler danışmanlığında hazırlamış olduğu "Koşullu Öz-Değer, Riskli İnternet Davranışları ve Siber Zorbalık/Mağduriyet Arasındaki İlişkinin İncelenmesi" isimli yüksek lisans tezinden üretilmiştir.

** Yrd. Doç. Dr., Bayburt Üniversitesi, Eğitim Bilimleri Bölümü, yeroglu45@gmail.com

*** Doç. Dr., Sakarya Üniversitesi, Eğitim Bilimleri Bölümü, gnguler@gmail.com
} 
ternet behaviors, internal and external contingencies of self-worth on cyberbullying and cybervictimization were investigated via structural equation modelling. In structural equation modelling, internal contingencies of self-worth was generated using virtue and family support. External contingencies of self-worth derived from academic competency, approval, and competition. Also Pearson correlation coefficients were utilized to investigate relationships among contingencies of selfworth, risky internet behaviors, cyberbullying and victimization. The goodness of fit indices $(\chi 2 / \mathrm{sd}=2.80, p=.000$ RMSEA $=.06, \% 90$ RMSEA CI $=.055-.064, \mathrm{CFI}=.92, \mathrm{TLI}=.91, \mathrm{RMR}=.06$ and $\mathrm{SRMR}=.06$ ) of model was well fit. According to path analysis, cyberbullying and cybervictimization were predicted positively by risky internet behavior and external contingencies of self-worth and negatively by internal contingencies of self-worth. The structural model explained $42 \%$ variances of cyberbullying/cybervictimization. These results were discussed in the light of the literature.

Keywords: Cyberbullying, risky internet behaviors, contingencies of self-worth.

\section{GİRIŞ̧}

Teknolojinin gelişmesiyle birlikte bilişim ve iletişim teknolojileri gençlerin yaşamının önemli bir parçası haline gelmiştir. Bilişim ve iletişim teknolojilerine erişimin kolaylaşması ve kullanımının yaygınlaşması gençler arasında yeni bir kültürün oluşmasına yol açmıştır. Bilişim ve iletişim teknolojileri gençlere diğer bireylerle eş zamanlı iletişim kurma olanağı vermekte, bilgi kaynaklarına hızlı bir şekilde ulaşmalarını sağlamakta ve sosyalleşmeleri açısından yeni olanaklar sunmaktadir (David-Ferdon ve Hertz, 2007). Bilişim ve iletişim teknolojilerinin bu olumlu yönlerinin yanında beraberinde getirdiği birçok olumsuz durum da bulunmaktadır. Bu olumsuz durumlara örnek olarak siber dolandırıcılık, çocukların cinsel açıdan istismarının kolaylaşması (grooming, çocuk pornografisi ve sexting) ve bireyleri şiddete ve uyuşturucuya yönelten web sitelerine erişim olanağının bulunması verilebilir. Scaglione ve Scaglione (2006) bilişim ve iletişim teknolojilerinin beraberinde getirdiği başlıca sorunlardan birisinin geleneksel zorbalığın sanal ortama taşınması olduğunu ifade etmiştir. Bu durum siber zorbalık olarak adlandırılmaktadır. Siber zorbalık, bir birey veya grubun bilişim ve iletişim teknolojilerini diğer bireylere zarar vermek amacıyla kötü niyetle ve tekrarlayan biçimde kullanması olarak tanımlanmaktadır (Belsey, 2008).

Siber zorbalık içeren davranışlar; SMS yoluyla, cep telefonu aracılığıyla video ve resim çekilerek, cep telefonuyla diğer bireyleri rahatsız ederek, sohbet odalarında e-posta yoluyla, anlık mesajlaşma sırasında veya web siteleri aracılığıyla gerçekleştirilmektedir (Smith, Mahdavi, Carvalho ve Tippett, 2006).

Siber zorbalıkla ilişkili araştırmalar, siber zorbalık ve mağduriyetin bireylerin sosyal, akademik ve duygusal yaşamları üzerinde çok ciddi olumsuz etkilerinin bulunduğunu göstermektedir. Arıcak (2009) tarafından yapılan araştırmada siber zorbalık yapmayan ve siber zorbalığa maruz kalmayan grubun siber zorba ve mağdurlardan daha az psikiyatrik belirti gösterdiği bulunmuştur. Hinduja ve Patchin (2009) siber mağduriyetin stres yaratıcı yaşam koşullarıyla birleştiğinde bireylerin intihar etmeye kadar varabilen davranışlar gösterdiğini bulmuştur. Siber zorbalığa maruz kalmanın yanında siber zorbalık yapmanın da çeşitli sorunlarla ilişkili olduğu belirlenmiştir. Arıcak (2009) diğer bireylere düşmanca duygular taşımanın ve psikotizmin siber zorbalık yapmayı olumlu yönde yordadığını bulmuştur. Pornari ve Wood (2010) da siber zorbalığın yoğun öfke duygusu taşımayla ilişkili olduğunu belirlemiştir.

Siber zorbalığın çeşitli akademik, duygusal ve sosyal sorunlarla ilişkili olması araştırmacıları siber zorbalığın temelinde yatan etmenleri araştırmaya yöneltmiştir. Bu bağlamda siber zorba ve mağdurların ebeveynleriyle kurdukları duygusal bağların yetersiz olduğu bulunmuştur (Ybarra, 2004; Ybarra ve Mitchell, 2004a; Ybarra, Mitchell, Finkelhor ve Wolak, 2007). Pornari ve Wood (2010) siber zorbalığ ahlaki açıdan mantıksallaştıran, şiddete eğilimli ve saldırganca davranarak istediklerini elde 
edeceklerine inanan bireylerin daha çok siber zorbalık yaptığını bulmuştur. Calvete, Orue, Estevaz, Villardon ve Padilla (2010) da siber zorbalığın en önemli nedenlerinden birisinin şiddetin mantıksallaştırılması olduğunu belirlemiştir.

Erdur-Baker (2010) siber zorbalıkla ilişkili en önemli değişkenlerden birisinin riskli internet kullanımı olduğunu belirtmiştir. Riskli internet kullanımı internette kişisel bilgilerin (örneğin internette tanıştığ 1 birisine fotoğrafını yollama) paylaşılmasını, internette tanıştığ iletişime geçilmesini, internette tanışılan kişiyle yüz yüze ortamda buluşulmasını, pornografik, intiharı özendirici, uyuşturucu kullanmaya yönelten ve belli bir grubu aşağılayıcı web sitelerine girilmesini, internette şaka ve kaba yorumlar yapılmasını, internetteyken birisinin bilerek utandırılmasını içermektedir (Dowell, Burgess ve Cavanaugh, 2009; Valkenburg ve Soeters, 2001). Erdur-Baker ve Tanrıkulu (2010) riskli internet kullanımının siber zorbalık ve mağduriyete yol açtı̆̆ını bulmuştur.

Siber zorbalıkla ve mağduriyetle ilişkili olarak ele alınabilecek bir diğer kavramın koşullu özdeğer alanları olduğu görülmektedir. Koşullu öz-değer alanları bireylerin öz-değerlerini yapılandıracakları çeşitli alanlara işaret etmekte ve koşullu öz-değer modeli çerçevesinde ele alınmaktadır. Koşullu öz-değer modeline göre bireylerin öz-değerlerini yapılandırabilecekleri yedi olası alan (onay alma, aile desteği, fiziksel görünüm, rekabet, akademik yeterlik, Tanrı sevgisi ve erdem) bulunmakta ve bireyin özdeğeri en çok bu alanlarda yaşanan başarı ya da başarısızlıklardan etkilenmektedir. Araştırmalar bireyin öz-değerini yapılandırdığı alanın davranışlarını etkilediğini göstermektedir. Örneğin öz-değerini erdem alanında yapıland1ran bireylerin vaktini daha çok gönüllü yardım faaliyetiyle, akademik alanda yapılandıran bireylerin ders çalışmakla ve Tanrı sevgisi alanında yapılandıran bireylerin ibadet etmekle geçirdiği bulunmuştur (Crocker, Karpinski, Quinn ve Chase, 2003). Stefanone, Lackaff ve Rosen (2010) bireylerin öz-değerini yapılandır- dıkları alanların yalnızca gerçek yaşamdaki değil sanal ortamdaki davranışlarını da etkilediğini ifade etmektedir. Söz konusu araştırmacılar tarafından yapılan araştırmada özdeğerini fiziksel görünüm alanında yapıland1ran bireylerin sanal ortamda kişisel bilgilerini paylaşmaya daha eğilimli olduğu görülmüştür.

\subsection{Araştırmanın Amacı}

$\mathrm{Bu}$ araştırmanın amacı riskli internet davranışları, koşullu öz-değer alanları ve siber zorbalık arasındaki ilişkiyi incelemektir. Bireylerin özdeğerlerini yapılandırdıkları alanların sanal ortamdaki davranışlarını da etkilediğinin ortaya konması bu alanların siber zorbalık ve mağduriyetle ilişkili olabileceğini düşündürmektedir. Bunun yanında riskli internet davranışlarının da işin içine katılması siber zorbalık ve mağduriyete yol açan etmenlerin daha iyi anlaşılmasını sağlayacak, araştırmacılara bu konuda iç görü kazandıracak ve sonraki araştırmalara ışık tutacaktır. Ayrıca hangi öz-değer alanlarının siber zorbalık ve mağduriyete yol açtığ1nın bulunması risk altında bulunan bireylerin belirlenmesi açısından önemli ipuçları sağlayacaktır.

\section{YÖNTEM}

\subsection{Araştırmanın Modeli}

Araştırma ilişkisel tarama modeline dayalı olarak sürdürülmüştür. İlişkisel tarama modelleri iki veya daha çok sayıdaki değişken arasında birlikte değişimin varlığını ve/veya derecesini belirlemeyi amaçlayan araştırma modelleridir. İlişkisel tarama modeli gerçek bir neden-sonuç ilişkisi vermemekle birlikte bir değişkendeki durumun bilinmesi halinde ötekinin kestirilmesine olanak sağlamaktadır (Karasar, 2006, s. 82). Bu araştırmada ilişkisel-tarama modeli aracılığıyla riskli internet davranışlarının ve koşullu öz-değerin siber zorbalık ve mağduriyet üzerindeki yordayıcı etkisinin incelenmesi amaçlanmıştır.

\subsection{Araștırmanın Çalıșma Grubu}


Araştırmanın evrenini 2011-2012 eğitimöğretim yılında Sakarya Üniversitesi Eğitim Fakültesi'nde öğrenim gören öğrenciler oluşturmaktadır. Araştırmanın örneklemini ise bu evrenden uygun örnekleme yöntemiyle seçilen 505 üniversite öğrencisi oluşturmaktadır. Araştırma örneklemini oluşturan öğrencilerin 360'1 kız (\% 71.1), 145’i (\% 28.5) erkektir. Araştırmaya katılan öğrencilerin 282 tanesi 20 yaşında veya altında (\% 55.8), 223 tanesi 20 yaşının üstündedir (\% 44.2).

\subsection{Veri Toplama Araçları}

Araştırmada kullanılan veriler kişisel bilgi formu, Riskli İnternet Davranışları Anketi, Yenilenmiş Siber Zorbalık Envanteri ve Koşullu Öz-Değer Ölçeği aracılığıyla toplanmıştır.

Kişisel Bilgi Formu: Araştırmacı tarafından geliştirilen Kişisel Bilgi Formunda cinsiyet, yaş ve ailenin aylık geliri ile ilgili sorular yer almaktadir.

Riskli İnternet Davranışları Anketi: Riskli internet davranışlarını ölçmek amacıyla geliştirilen Riskli İnternet Davranışları Anketinin geliştirilmesi sürecinde öncelikle alanyazın incelemesi yapılmıştır. Alanyazında internette tanımadığı kişilerle kişisel bilgilerini paylaşma; internette tanımadığı kişilere buluşma teklif etme veya onların buluşma teklifini kabul etme; internette şiddet içerikli, pornografik, kendi kendine zarar vermeyi ve intiharı özendirici ve belli bir grubu aşağılayıcı web sitelerine girme; internetten yasadışı içerikli materyaller indirme ve video paylaşım sitelerinde uygunsuz video paylaşmanın riskli internet davranışları olarak kabul edildiği belirlenmiştir. Riskli İnternet Davranışları Anketi, söz konusu davranışları ölçmek amacıyla hazırlanmış 28 madde içermektedir. Anketin güvenirliği .72 olarak bulunmuştur.

Koşullu Öz-Değer Ölçeği: Crocker ve diğerleri (2003) tarafından bireylerin olası öz-değer alanlarını belirlemek amacıyla geliştirilmiştir. Koşullu Öz-Değer Ölçeği 35 maddeden ve 7 alt boyuttan oluşmaktadır. Bu alt boyutlar; onay alma, aile desteği, rekabet, fiziksel görünüm, akademik yeterlik, Tanrı sevgisi ve erdemdir. Katılımclar maddelerin kendilerine uygunluk derecesini; (1) Kesinlikle Katılmiyorum, (2) Katılmiyorum, (3) Bazen Katılmiyorum, (4) Kararsızım, (5) Bazen Katılıyorum, (6) Katılıyorum ve (7) Kesinlikle Katılıyorum olmak üzere 7'li likert tipi bir derecelendirme kullanarak belirtmektedir. Her bir alt ölçeğe ilişkin toplam puan, o alt ölçekte yer alan maddelerin toplanıp beşe bölünmesiyle elde edilmektedir. Ölçekten ölçeğin bütününe ilişkin toplam puan elde edilememektedir. Her bir alt ölçek için toplam puanın yüksekliği, öz-değerin söz konusu alt ölçeğin temsil ettiği alanda yapılandırılma düzeyinin yüksekliğine işaret etmektedir. Onay alma, fiziksel görünüm, akademik yeterlik ve rekabet alt ölçeklerinden alınan puanların ortalamasının alınması yoluyla elde edilen puan, öz-değerin dışsal alanlarda yapılandırılma düzeyini; Tanrı sevgisi, aile desteği ve erdem alt ölçeklerinden alınan puanların ortalamasının alınması yoluyla elde edilen puan ise öz-değerin içsel alanlarda yapılandırılma düzeyini göstermektedir.

Koşullu Öz-Değer Ölçeğinin Türkçeye uyarlaması Çetin, Akın ve Eroğlu (2011) tarafından yapılmıştır. Yapılan çalışmada açımlayıcı faktör analizinde toplam varyansın \% 66.63'ünü açıklayan ve 7 alt boyutlu bir yapı elde edilmiştir. Faktör analizi sonucunda 6. ve 34. maddeler 30 kriterini (Büyüköztürk, 2008) karşılamadığı için ölçekten çıkarılmıştır. Bu iki madde dışındaki maddelerin orijinal formadakiyle ayn boyutta yer aldığı görülmüştür. Yapılan doğrulayıcı faktör analizi çalışmasında ise ölçeğin yedi alt boyutta uyum verdiği $(x 2 / \mathrm{sd}=1.91$, RMSEA=.04, NFI=.97, CFI=.98, IFI=.99, RFI=.96, GFI=.96 ve AGFI=.94) görülmüştür (Hu ve Bentler, 1999). İç tutarlık katsayıları ise aile desteği alt ölçeği için .91, rekabet alt ölçeği için .89, fiziksel görünüm alt ölçeği için .88, Tanrı sevgisi alt ölçeği için .88, akademik yeterlik alt ölçeği için .86, erdem alt ölçeği için .82 ve onay alma alt ölçeği için .82 olarak bulunmuştur. Test-tekrar test güvenirliği ise aile desteği alt boyutu için .76, rekabet alt boyutu için .68, 
fiziksel görünüm alt boyutu için .89, Tanrı sevgisi alt boyutu için .79, akademik yeterlik alt boyutu için .77 , erdem alt boyutu için .82 ve onay alma alt boyutu için ise .86 olarak belirlenmiştir.

Yenilenmiş Siber Zorbalık Envanteri: Siber zorbalık ve mağduriyet olmak üzere iki paralel formdan oluşan envanter Topçu ve ErdurBaker (2010) tarafından geliştirilmiştir. 28 maddeden oluşan envanterde katılımcılar her bir maddenin uygunluk derecesini, (1) Hiç, (2) Bir kez, (3) İki-üç kez ve (4) Üçten çok olmak üzere 4'lü likert tipi bir derecelendirme kullanarak belirtmektedir. Envanterin hem siber zorbalık hem siber mağduriyet formundan alınabilecek en düşük puan 14, en yüksek puan 56 'dır. Siber zorbalık formundan yüksek puan alınması siber zorbalık içeren eylemlerin yapılma sıklığına, siber mağduriyet formundan yüksek puan alınması ise siber mağduriyet içeren eylemlerin yüksekliğine işaret etmektedir. Doğrulayıcı faktör analizinden elde edilen uyum iyiliği indeksleri hem siber zorbalık ( $\mathrm{RMSEA}=.06, \mathrm{GFI}=.93$ ve $\mathrm{CFI}=.93$ ) hem de siber mağduriyet (RMSEA=.06, GFI=.93, CFI=.89) formunun yapı geçerliğine sahip olduğunu göstermektedir. Envanterin iç tutarlık katsayıları siber zorbalık formu için .82, siber mağduriyet formu için .75 olarak bulunmuştur.

\subsection{Verilerin Toplanması ve Analizi}

Veriler Sakarya Üniversitesi Eğitim Fakültesi'nin çeşitli bölümlerinde öğrenim gören 528 üniversite öğrencisine uygulanmıştır. Katılımcılara araştırmaya katılımın gönüllülüğe dayalı olduğu bildirildikten sonra isteyen katılımcilara uygulanmıştır. Uygulama sırasında boş bırakılan ya da ciddi olarak doldurulmadığ tespit edilen veriler analize dâhil edilmemiştir. Bu nedenle 528 katılımcıya uygulama yapılmasına karşın 505 öğrenciden elde edilen veri analize katılmıştır. Elde edilen verilerin analizinde SPSS 11.5 ve LISREL 8.54 programları kullanılmıştır. Riskli internet davranışları, siber zorbalık, mağduriyet ve Koşullu Öz-Değer Ölçeği'nin alt boyutlarını oluşturan rekabet, fiziksel görünüm, Tanrı sevgisi, onay alma, erdem, akademik yeterlik ve aile desteği arasındaki ilişkiler Pearson Momentler Çarpım Korelasyon Katsayısı ile elde edilmiştir. Siber zorbalık ve mağduriyetin riskli internet davranışları, içsel ve dışsal öz-değer alanları tarafından yordanmasına ilişkin bulgular yapısal eşitlik modellemesi (YEM) aracılığıyla toplanmiştır.

\section{BULGULAR}

3.1. Riskli İnternet Davranışları, Siber Zorbalık, Siber Mağduriyet ve Koşullu Öz- Değer Ölçeğinin Alt Boyutları Arasındaki İlişkilere Yönelik Bulgular

Riskli internet davranışları, siber zorbalık, mağduriyet ve Koşullu Öz-Değer Ölçeğinin alt boyutları arasındaki ilişkilere yönelik bulgular Tablo 1'de gösterilmiştir.

Tablo 1 incelendiğinde riskli internet davranışlarının siber zorbalık $(\mathrm{r}=.40, \mathrm{p}<.01)$ ve siber mağduriyet $(\mathrm{r}=.36, \mathrm{p}<.01)$ ile pozitif ve orta düzeyde, fiziksel görünüm $(\mathrm{r}=.22, \mathrm{p}<.01)$ ile pozitif düşük düzeyde ve erdem $(\mathrm{r}=-.15, \mathrm{p}<.01)$ ve aile desteği $(r=-.19, p<.01)$ ile ise negatif düşük düzeyde ilişkili olduğu görülmüştür. 
Tablo 1. Riskli İnternet Davranışları, Siber Zorbalık, Mağduriyet ve Koşullu Öz-Değer Ölçeğinin Alt Boyutları Arasındaki İlişkiler

\begin{tabular}{|c|c|c|c|c|c|c|c|c|c|c|}
\hline Değişkenler & 1 & 2 & 3 & 4 & 5 & 6 & 7 & 8 & 9 & 10 \\
\hline \multicolumn{11}{|l|}{$\begin{array}{l}\text { 1.Riskli internet } \\
\text { davranışları }\end{array}$} \\
\hline 2.Siber zorbalık & $.40^{* * *}$ & & & & & & & & & \\
\hline $\begin{array}{l}\text { 3.Siber mağduri- } \\
\text { yet }\end{array}$ & $.36^{* *}$ & $.52^{* *}$ & & & & & & & & \\
\hline 4.Rekabet & .008 & .09 & -.008 & & & & & & & \\
\hline 5.Onay alma & .08 & .01 & .02 & $.22^{* *}$ & & & & & & \\
\hline $\begin{array}{l}\text { 6.Akademik } \\
\text { yeterlik }\end{array}$ & $-.11^{*}$ & .02 & .02 & $.62^{* *}$ & $.18^{* *}$ & & & & & \\
\hline $\begin{array}{l}\text { 7. Fiziksel görü- } \\
\text { nüm }\end{array}$ & $.22^{* *}$ & $.14^{* *}$ & .08 & $.37^{* *}$ & $.36^{* *}$ & $.17^{* *}$ & & & & \\
\hline 8.Tanrı sevgisi & $-.10^{*}$ & -.004 & -.003 & $.44^{* *}$ & .04 & $.44^{* *}$ & -.01 & & & \\
\hline 9.Erdem & $-.15^{* *}$ & $-.24^{* * *}$ & $-.18^{* *}$ & $.33^{* *}$ & .04 & $.40^{* *}$ & $-.12^{* *}$ & $.52^{* *}$ & & \\
\hline 10.Aile desteği & $-.19^{* *}$ & $-.23^{* *}$ & $-.24^{* *}$ & $.30^{* *}$ & $.15^{* *}$ & $.42^{* *}$ & .02 & $.40^{* *}$ & $.65^{* *}$ & \\
\hline Ortalama & 28.82 & 16.57 & 16.92 & 5.15 & 3.96 & 5.24 & 3.75 & 5.68 & 5.69 & 5.56 \\
\hline Standart sapma & 5.55 & 5.33 & 4.75 & 1.29 & 1.19 & 1.10 & 1.23 & 1.24 & 1.16 & 1.07 \\
\hline${ }^{*} \mathrm{p}<.05,{ }^{* *} \mathrm{p}<.01$ & & & & & & & & & & \\
\hline
\end{tabular}

Siber zorbalığın siber mağduriyet $(r=.52, \mathrm{p}<.01)$ ile pozitif orta düzeyde, fiziksel görünüm ( $\mathrm{r}=.14, \mathrm{p}<.01)$ ile pozitif düşük düzeyde; erdem $(\mathrm{r}=-.24, \mathrm{p}<.01)$ ve aile desteği $(\mathrm{r}=-.23, \mathrm{p}<.01)$ ile ise negatif düşük düzeyde ilişkili olduğu belirlenmiştir. Rekabetin onay alma $(\mathrm{r}=.22, \mathrm{p}<.01)$ ile pozitif düşük düzeyde, akademik yeterlik $(\mathrm{r}=.62, \mathrm{p}<.01)$ ve fiziksel görünüm $(\mathrm{r}=.37, \mathrm{p}<.01)$ ile ise pozitif orta düzeyde ilişkili olduğu bulunmuştur. Onay almanın fiziksel görünüm $(\mathrm{r}=.36, \mathrm{p}<.01)$ ile pozitif orta düzeyde, aile desteği $(\mathrm{r}=.15, \mathrm{p}<.01)$ ve akademik yeterlik $(\mathrm{r}=.18$, $\mathrm{p}<.01)$ ile ise pozitif düşük düzeyde ilişkili olduğu saptanmıştır. Akademik yeterliğin fiziksel görünüm ( $\mathrm{r}=.17, \mathrm{p}<.01)$ ile pozitif düşük düzeyde, Tanrı sevgisi $(\mathrm{r}=.44, \mathrm{p}<.01)$, erdem $(\mathrm{r}=.40, \mathrm{p}<.01)$ ve aile desteği $(\mathrm{r}=.42, \mathrm{p}<.01)$ ile ise pozitif orta düzeyde ilişkili olduğu görülmüştür. Tanr1 sevgisinin erdem $(\mathrm{r}=.52, \mathrm{p}<.001)$ ve aile desteği $(r=.40, p<.01)$ ile pozitif orta düzeyde ilişkili olduğu bulunmuştur. Erdem ile aile desteğinin ise pozitif orta düzeyde ilişkili olduğu $(r=.65, p<.01)$ belirlenmiştir.

3.2. Siber Zorbalıkla İlişkili Davranışların, Riskli İnternet Davranışları, İçsel Öz- Değer Alanları ve Dışsal Öz-Değer Alanları Tarafından Yordanmasına İlişkin Yapısal Model Analizi

Yapısal eşitlik modeli oluşturulmadan önce veriler bir takım işlemlere tabii tutulmaktadır. Şimşek (2007) bu işlemleri verilerin normallik varsayımını karşılaması ve uç değerlerin temizlenmesi olarak sıralanmaktadır. Normallik varsayımına uygunluk Lilliefors testi aracıllğgıyla incelenmiş ve fiziksel görünüm alt boyutunun normallik varsayımını karşılamadığı belirlenmiştir. Yine her değerin gözlenen değeri ile normal dağılım olduğu takdirde beklenen değeri arasındaki farkların noktalandığı detrended normal olasılık grafiğinden yapilan izlemeler sonucu Tanrı sevgisi değişkeninin 
normallik varsayımını karşılamadığı görülmüştür. Diğer değişkenlerin ise bu izlemeler sırasında normalden çok ciddi sapmalar göstermediği bulunmuştur. Mahalanobis uzaklık değerlerinin hesaplanması sonucunda 33 veri uç değer olarak belirlenmiş ve analize katılmamıştir.

Yapısal eşitlik modelinde dört örtük değişken belirlenmiştir. Bu örtük değişkenler siber zorbalık, riskli internet davranışları, içsel öz-değer alanları ve dışsal öz-değer alanlarıdır. Gösterge değişkenler incelendiğinde riskli internet davranışlarına ilişkin örtük değişkenin gösterge değişkenleri olarak Riskli İnternet Davranışları Anketi'nde yer alan maddeler seçilmiştir. İçsel öz-değer alanları örtük değişkeninin gösterge değişkenleri erdem ve aile desteği, dişsal özdeğer alanlarının örtük değişkeni ise akademik yeterlik, rekabet ve onay alma değişkenlerinden oluşmaktadır. Siber zorbalık örtük değişkeni ise siber zorbalık ve mağduriyet formundan elde edilen toplam puanlardan oluşturulmuştur. Yapısal eşitlik modelinin tahmin edilmesinde en yüksek olabilirlik (maximum likelihood) yönteminden yararlanılmıştır.

Yapısal eşitlik modelinden elde edilen uyum iyiliği indeksleri modelin kabul edilebilir düzeyde uyum verdiğini $(\chi 2 / \mathrm{sd}=2.80, p=.000$ RMSEA $=.06, \% 90$ RMSEA CI=.055-.064, $\mathrm{CFI}=.92$, TLI= .91, RMR=.06, SRMR=.06) göstermiştir (Hu ve Bentler, 1999).Yapısal eşitlik modeline ilişkin sonuçlar incelendiğinde riskli internet davranışları, içsel ve dişsal öz-değer alanları birlikte siber zorbalığın \% 42'sini açıklamaktadır. Yapısal eşitlik modeli incelendiğinde riskli internet davranışlarının ve dişsal öz-değer alanlarının siber zorbalığı pozitif biçimde yordadı̆̆ $\mathrm{p}<.05$ ve $\gamma=0.27, \mathrm{t}=3.60, \mathrm{p}<.05)$, içsel öz-değer alanlarının ise siber zorbalığ1 negatif yönde yordadığı $(\gamma=-0.42, \mathrm{t}=-5.42, \mathrm{p}<.05)$ dikkati çekmektedir. Kline (2005) standardize edilmiş katsayıların etki büyüklükleriyle ilgili olarak .10'dan küçük değerlerin küçük etkilere, .30 civarındaki değerlerin orta düzeydeki etkilere ve .50 ve üzerindeki değerlerin yüksek düzey- deki etkilere işaret ettiğini ifade etmektedir. Bu bağlamda riskli internet davranışlarının ve içsel ve dışsal öz-değer alanlarının siber zorbalıkla ilişkili davranışlar üzerindeki etkisinin orta düzeyde olduğu söylenebilir.

\section{TARTIŞMA}

$\mathrm{Bu}$ araştırmada riskli internet davranışları, içsel ve dışsal öz-değer alanlarının siber zorbalık üzerindeki etkisi incelenmiştir. Birçok araştırma (Erdur-Baker, 2010; Erdur-Baker ve Tanr1kulu, 2010; Ybarra ve Diener-West, 2008) riskli internet davranışlarının siber zorbalık ve mağduriyete yol açtığını ortaya koymuştur. Bu sonuç beklenen bir sonuç olarak değerlendirilebilir. Bireyin internette tanımadığı kişilerle iletişim kurması, onların kişisel bilgilerini ve resimlerini paylaşması, internette çeşitli sanal ortamlara erişimini sağlayan kullanıcı şifresini başkalarıyla paylaşmasının onun siber zorbalıkla ilişkili davranışlar açısından risk altında birakmaktadir.

Araştırmadan elde edilen bir diğer bulgu içsel öz-değer alanlarının siber zorbalık ve mağduriyeti negatif yönde yordadığıdır. Kurulan yapısal eşitlik modelinde içsel öz-değer alanları erdem ve aile desteği boyutlarıyla ölçülmüştür. Erdemin siber zorbalık ve mağduriyeti negatif yönde yordaması erdem ile siber zorbalık arasındaki ilişkiyi araştıran sınırlı sayıdaki (Pornari ve Wood, 2010; Williams ve Guerra, 2007; Almeida ve diğerleri, 2009) araştırma bulgusuyla örtüşmektedir. Pornari ve Wood (2010) ahlaki çözülmenin siber zorbalığı hızlandırdığını bulmuştur. Williams ve Guerra (2007) bireyin zorbalığın ahlaki açıdan kabul edilemez olduğunu düşünmesinin siber zorba ve mağdur olarak siber zorbalığa karışmasını önlediğini bildirmiştir. Almeida ve diğerleri (2009) ahlaki çözülmenin bireyin siber zorbalıktan ötürü suçluluk duymasını engellediğini ve davranışlarını gerekçelendirmesi ve mantıklaştırması sürecinde bireye dayanak sağladığını belirlemiştir.

İçsel öz-değer alanlarını oluşturan bir diğer boyut ise aile desteğidir. Yapılan araştırmalar (Ybarra ve Mitchell, 2004b; Ybarra ve Mitchell, 
2004a; Ybarra ve diğerleri, 2007) ebeveynlerle yetersiz duygular bağ kurulmasının siber zorbalık ve mağduriyeti olumlu yordadığını göstermiştir. Aile üyeleriyle kaliteli ilişsiler kuramayan bireylerin duygusal destek aramak amacıyla internete yöneldiği (Lei ve $\mathrm{Wu}, 2007$ ) göz önüne alındığında bu bireylerin internette siber zorbalıkla ilişkili davranışlara karıştığı görülmektedir. Dilmaç ve Aydoğan (2010) tarafından yapılan araştırmada da otoriter ebeveyn tutumunun siber zorbalık ve mağduriyete yol açtı̆̆ ebeveyn tutumunun siber zorbalık ve mağduriyeti önlediği bulunmuştur.

Araştırmada elde edilen bir diğer bulgu dişsal öz-değer alanlarının siber zorbalık ve mağduriyeti pozitif biçimde yordadığıdır. Dışsal özdeğer alanın ilk boyutunu rekabet oluşturmaktadır. Öz-değerini rekabet alanında yapıland1ran bireylerin rekabetlerini sanal ortama taş1maları ve rakiplerine siber zorbalık yapmaya çalışmaları ve bu süreçte siber zorbalığa maruz kalmaları olasıdır.

Araştırmada öz-değerini onay alma alanında yapılandıran bireylerin siber zorbalıkla ilişkili davranışlara karışma oranının çok az olduğu görülmektedir. Bunun nedeni üniversite öğrencilerinin özerk davranabilme becerisini kazanmiş olması ve akran grubunun birey üzerindeki etkisini yitirdiği bir gelişim sürecinde bulunmaları olabilir. Farklı gelişim dönemlerinde bulunan bireyler üzerinde yapılan araştırmalar daha farklı sonuçlar verebilir. Örneğin akran grubunun birey üzerindeki etkisinin yoğun olarak hissedildiği ergenlik dönemindeki bireyler üzerinde yapılan bir araştırmada, onay almanın siber zorbalık/mağduriyet üzerindeki etkisinin daha fazla olduğuna dair bulgular elde edilmesi söz konusu olabilir.
Araştırma bulguları öz-değerin akademik yeterlik alanında yapılandırılmasının siber zorbalıkla ilişkili davranışları pozitif yönde yordadığını ortaya koymaktadır. Crocker ve diğerleri (2003) öz-değerini akademik yeterlik alanında bireylerin başarılı olmak için çalışmaya ve başarısızlıktan kaçınmaya oldukça güdülenmiş olmasına rağmen derslerden yüksek notlar alamadığını belirtmekte ve bunu öz-değerini akademik yeterlik alanında bireylerin öğretim y1l boyunca daha stresli olmasına, zaman baskısını daha yoğun yaşamasına, dersleri yürüten öğretim elemanlarıyla sık sık tartışmasına, zor bir etkinlik karşısında çaba göstermeyi bırakmasına ve olumsuz öz-değerlendirici düşüncelerin etkisini altına girmeye eğilimli olmasına bağlamaktadır. Birey öz-değerini akademik alanda yapılandırmasına rağmen bu alanda başarılı olamadığında bu stres yaratıcı durumdan kurtulmak için çeşitli çözüm stratejileri geliştirecektir. $\mathrm{Bu}$ araştırmadan elde edilen bulgular bu çözüm stratejilerinden birisinin siber zorbalık olduğunu göstermektedir.

$\mathrm{Bu}$ araştırmanın çeşitli sınırlılıkları bulunmaktadır. Bu sinırlılıklardan ilki uygun örnekleme yönteminin kullanılmasıdır. Araştırmanın bir diğer sınırlılığını üniversite öğrencileri üzerinde yürütülmesi oluşturmaktadır. Bu araştırma bağlamında çeşitli önerilerde bulunulabilir. İlk olarak üniversite öğrencileri dışında ergenler başta olmak üzere farklı gruplarla çalışılması önerilebilir. Araştırma bulgularına dayalı olarak yapılabilecek bir diğer öneri siber zorbalığın farklı psikolojik yapılarla ilişkinin incelenmesinin kavramın irdelenmesi açısından önemli olduğu ifade edilebilir. Ayrıca siber zorbalığı önlemeye yönelik müdahale programlarının riskli internet davranışlarını ve gerçek yaşamın çeşitli boyutlarını kuşatıcı öğeler dikkate alınarak hazırlanması gerektiği ifade edilebilir. 


\section{Kaynakça}

Almeida, L., Correia, I., Garcia, S., Marinho, S., Gomes, S. ve Esteves, C. (2009). Are Moral Disengagement and Emphaty Related to Cyberbullying Practices? http://www.gold. ac. uk/media/Abstract_book_1 ${ }^{\text {st }}$ _Workshop.pdf adresinden 13.02.2011 tarihinde erişilmiştir.

Arıcak, O. T. (2009). Psychiatric symptomatology as a predictor of cyberbullying among university students. Eurasian Journal of Educational Research, 34, 167-184.

Belsey, B. (2008). Cyberbullying an Emerging Threat to the Always on Generation. http: //www. cyberbullying.ca/pdf/Cyberbullying Article by Bill Belsey. pdf adresinden 12. 11. 2010 tarihinde erişilmiştir.

Büyüköztürk, Ş. (2008). Veri Analizi El Kitabı. Ankara: Pegem Akademi.

Calvete, E., Orue, I., Estevaz, A., Villardon, L. ve Padilla, P. (2010). Cyberbullying in adolescents: modalities and aggressor's profile. Computers in Human Behavior, 26, 1128-1135.

Crocker, J. F., Karpinski, A., Quinn, D. M. ve Chase, S. K. (2003). When grade determine self-worth: consequences of contingent self-worth for male and female engineering and psychology majors. Journal of Personality and Social Psychology, 5, 507-516.

Çetin, B., Akın, A. ve Eroğlu, Y. (2011). Koşullu öz-değer ölçeğinin geçerlik ve güvenirliği. Uluslararası Insan Bilimleri Dergisi, 8 (1), 410-426.

David, F. ve Hertz, M. F. (2007). Electronic Media, Violence, and Adolescents: An Emerging Health Problem. Journal of Adolescent Health, 41, 1-5.

Dilmaç, B. ve Aydoğan, D. (2010). Parental attitudes as a predictor of cyberbullying among primary school children. International Journal of Human and Social Sciences, 5, 649-653.

Dowell, E. B., Burgess, A. W. ve Cavanaugh, A. J. (2009). Clustering of internet risk behaviors in a middle school student population. Journal of School Health, 79 (1), 547-553.

Erdur-Baker, Ö. (2010). Cyberbullying and its correlation to traditional bullying, gender, and frequent and risky usage of internet-mediated communication tools. New Media \& Society, 12, 109-125.

Erdur-Baker, Ö. ve Tanrıkulu, İ. (2010). Psychological consequences of cyberbullying experiences among turkish secondary school children. Procedia-Social and Behavioral Sciences, 2, 2771-2776.

Hinduja, S. ve Patchin, J. W. (2009). Bullying Beyond the Schoolyard: Preventing and Responding to Cyberbullying. California: Corwin Press.

Hu, L. T. ve Bentler, P. M. (1999). Cutoff criteria for fit indices in covariance structure analysis. Structural Equation Modelling, 6 (1), 1-55.

Karasar, N. (2006). Bilimsel Araştırma Yöntemi. Ankara: Nobel Yayın Dağıtım.

Kline, R. B. (2005). Principles and Practice of Structural Equation Modelling. New York: Guilford Publications.

Lei, L. ve Wu, Y. (2007). Adolescents' paternal attachment and internet use. Cyberpsychology \& Behavior, $10,633-639$.

Pornari, D. C. ve Wood, J. (2010). Peer and cyber aggression in secondary school students: the role of moral disengagement, hostile attribution bias, and outcome expectancies. Aggressive Behavior, 36, 81-94.

Scaglione, J. ve Scaglione, A. R. (2006). Bully-Proofing Children: A Practical, Hands-On Guide to Stop Bullying. Plymouth: Rowman \& Littlefield Publishers. 
Smith, P., Mahdavi, J., Carvalho, M. ve Tippett, N. (2006). An Investigation into Cyberbullying, Its Forms, Awareness, and Impact, the Relationship between Age and Gender in Cyberbullying. http:// www. antibullyingalliance.org.uk adresinden 25.11. 2010 tarihinde erişilmiştir.

Stefanone, M. A., Lackaff, D. J. ve Rosen, D. (2010). Contingences of Self-Worth and Social Networking Site Behavior. http:// www. liebertonline.com adresinden 15. 02.2011 tarihinde erişilmiştir.

Şimşek, Ö. F. (2007). Yapısal Eşitlik Modellemesine Giriş. Ankara: Ekinoks.

Topçu, Ç. ve Erdur-Baker, Ö. (2010). The Revised Cyberbullying inventory (CBI): validity and reliability. Procedia-Social and Behavioral Sciences, 5, 660-664.

Valkenburg, P. M. ve Soeters, K. M. (2001). Children's Positive and Negative Experiences with Internet. Communication Research, 28, 652-675.

Williams, K. R. ve Guerra, N. G. (2007). Prevalence and Predictors of Internet Bullying. Journal of Adolescent Health, 41, 14-21.

Ybarra, M. L. (2004). linkages between depression symptomatology and internet harassment among young regular internet users. CyberPsychology \& Behavior, 7, 247-257.

Ybarra, M. ve Diener-West, M. (2008). How Protective Against Child and Adolescent Behavior is a Violence-Free Media Diet? http://is4k.com/presentations/how-protective-against-child-andadolescentaggressive- behavior-is-a-violence-free-media-diet/ adresinden 01. 12. 2010 tarihinde erişilmiştir.

Ybarra, M. L. ve Mitchell, K. J. (2004a). Youth engage in online harassment: associations with caregiverchild relationships, internet use, and personal characteristics. Journal of Adolescence, 27, 319-336.

Ybarra, M. L. ve Mitchell, K. J. (2004b). Online aggressor/targets, aggressors, and targets: A comparison of associated youth characteristics. Journal of Child Psychology and Psychiatry, 45, 1308-1316.

Ybarra, M. L., Mitchell, K. J., Finkelhor, D. ve Wolak, J. (2007). Internet prevention messages targeting the right online behaviors. Archives of Pediatrics \& Adolescent Medicine, 161, 138-145. 


\section{Extended Summary}

\section{Purpose}

The aim of this study was to investigate relationships among risky internet behaviors, internal and external contingencies of self-worth, and cyberbullying and cybervictimization.

\section{Methods}

This research was based on relational screening survey. Convenience samplig was utilized for nominating participants. 505 undergradute students from different departments of University of Sakarya took part in this study. Of the participants, 360 were female and 145 were male. The Socio-demographic Form, the Contingencies of Self-Worth Scale, the Risky Internet Behaviors Questionnaire, and the Revised Cyberbullying Inventory were used in this research. Socio-demographic form includes three questions in relation to gender, age, and family income. The Contingencies of Self-Worth Scale was developed by Crocker and colleagues (2003) and translated into Turkish by Çetin and colleagues (2011). This scale consists of seven subscales. These subscales are academic competency, God'love, virtue, family support, appearance, competency, and approval.. The Revised Cyberbullying Inventory was developed by Topçu and Erdur-Baker (2010). Revised Cyberbullying Inventory consists of two paralel forms; one for cyberbullying and one for cybervictimization. In cyberbullying form, higher scores indicate more frequent cyberbullying experience. On the other hand, higher scores indicate more frequent cybervictimization experience. Risky Internet Behaviors Questionnaire was developed by researcher. It includes 28 items. Data were gathered by the researcher in class. Participants were informed about the aim of the study and the procedures in which they are engaged. Participation in this research is completely voluntarily. Participants were given guaranty that data about themselves would be kept confidential. To predict cyberbullying and cybervictimization from risky internet behaviors, external and internal contingencies of self-worth structural equation modelling was used. In structural equation modelling, academic competency, approval, and competency were explained by external contingencies of self-worth. On the other hand virtue and family support were explained by internal contingencies of self-worth. Also relationships among domains of contingencies of self-worth, risky internet behaviors, cyberbullying and cybervictimization were calculated using Pearson correlations. Data were analyzed using SPSS 11.5 and LISREL 8.54.

\section{Results}

According to Pearson Correlation Coefficients, risky internet behaviors were positively related with cyber bullying $(\mathrm{r}=.40, \mathrm{p}<.01)$, cyber victimization $(\mathrm{r}=.36, \mathrm{p}<.01)$, physical appearance $(\mathrm{r}=.22, \mathrm{p}<.01)$, and negatively associated with virtue $(\mathrm{r}=-.15, \mathrm{p}<.01)$ and family support $(\mathrm{r}=-.19, \mathrm{p}<.01)$. Cyberbullying were positively associated with cybervictimization $(\mathrm{r}=.52, \mathrm{p}<.01)$ and physical appearance $(\mathrm{r}=.14, \mathrm{p}<.01)$ and negatively associated with virtue $(\mathrm{r}=-.24, \mathrm{p}<.01)$ and family support $(\mathrm{r}=-.23, \mathrm{p}<.01)$. Competition were positively related with physical appearence $(\mathrm{r}=.36, \mathrm{p}<.01)$, family support $(\mathrm{r}=.15, \mathrm{p}<.01)$, and academic competency $(\mathrm{r}=.18, \mathrm{p}<.01)$. Academic competency was positively related with physical appearance $(\mathrm{r}=.17, \mathrm{p}<.01)$, virtue $(\mathrm{r}=.40, \mathrm{p}<.01)$, and family support $(\mathrm{r}=.42, \mathrm{p}<.01)$. Finally, it was found that virtue and family support was positively related each other $(\mathrm{r}=.65, \mathrm{p}<.01)$. The overall results of this research supported basic assumptions of this study. The goodness of fit indices ( $\chi 2 / \mathrm{df}=2.80, p=.000 \mathrm{RMSEA}=.06, \% 90$ RMSEA CI= .055-.064, CFI=.92, TLI= .91, RMR=.06 ve SRMR=.06) indicated that the model were accepted fit. According to path analysis results, cyberbullying/cybervictimization was predicted positively by external contingencies of self-worth and risky internet behaviors and negatively predicted by internal contingencies of self-worth. The model explained $42 \%$ variances of cyberbullying/cybervictimization. 


\section{Discussion}

In this research, it was found that risky internet behaviors were positively predicted cyberbullying and victimization. According to these results, people who engage in risky internet behaviors such as communicating with unknown person, sharing personal information with them, and watching pornography are under risk for cyberbullying. These results were matched found by Erdur-Baker (2010), Erdur-Baker and Tanrikulu (2010), and Ybarra and Diener-West (2008).

Another findings of this study showed that internal contingencies of self-worth negatively predicted cyber bullying and victimization. These results were consistent with Pornari and Wood (2010)'s and Williams and Guerra (2007)'s researches. Pornari and Wood (2010) found that moral disengagement facilitates cyber bullying. Williams and Guerra (2007) reported that individuals who consider bullying as immoral action are less involved in cyber bullying. The dimension of internal contingencies of selfworth is family support. Having poor emotional bond with his /her parents prevented individuals from involving cyberbullying as bully or victim. Based on these findings, it can be said that family support is necessary for struggling with cyberbullying.

The other findings of this study were that external contingencies self-worth positively predicted cyberbullying. External contingencies of self-worth included competition, academic competence, and approval. Based on findings of this study, it can be said that people who have competition contingencies of selfworth bring competition into virtual life. They might cyber bully or be cyberbullying in this process. Individual who have approval contingencies of self-worth are less involved in cyberbullying. These findings may be derived from that university students can behave autonomously. Also they are in developmental stage in which peer influences on them increasingly lose its important. Different studies with different populations such as adolescents cause different results. Individuals with academic contingencies of self-worth are likely to be cyberbully and cyber victim. Because they utilizing cyberbullying behavior for escape tension related to academic failure. Finally, based on findings of this study, it can be said that prevention programs should be prepared for cyberbullying. 